\title{
The Effect of Tryptophan Depletion on Mood in Medication-Free, Former Patients with Major Affective Disorder
}

\author{
Marco Leyton, Ph.D., Simon N. Young, Ph.D., Pierre Blier, M.D., Ph.D., Mark A. Ellenbogen,
} M.Sc., Roberta M. Palmour, Ph.D., A-Missagh Ghadirian, M.D., and Chawki Benkelfat, M.D.

Acute tryptophan depletion (ATD) induces transient clinical relapse in medicated patients with major affective disorder. Our objective was to determine whether this effect persists once patients are euthymic and off antidepressants. Thus, we examined the effects of ATD in fully remitted, medication-free, former patients with major depression $(n=14)$. ATD had no significant effect on mood. These results suggest that the previous report that ATD substantially lowers mood in pharmacologically treated patients reflects a reversal of mechanisms involved in the therapeutic effects of antidepressants. Alternatively, ATD might induce clinical relapse only in subgroups that have yet to be identified. [Neuropsychopharmacology 16:294-297, 1997] (C) 1997 American College of Neuropsychopharmacology
KEY WORDS: Tryptophan depletion; Serotonin; Depression; Relapse

Acute tryptophan depletion (ATD) is a technique that causes a dramatic lowering of both plasma concentrations of free tryptophan and the rate of serotonin (5-hydroxytryptamine, 5-HT) synthesis in the human brain (Nishizawa et al. submitted). ATD also has been reported to provoke symptoms resembling clinical relapse in patients with major affective disorder that was recently improved by antidepressant medication (Delgado et al. 1990). These authors suggested that antidepressant response requires the functional integrity of the 5-HT system. In comparison, we have found that ATD induces modest mood lowering in drug-free psychiatrically normal women (Ellenbogen et al. 1996) and in male first-degree relatives of patients with major affec-

From the Department of Psychiatry (ML, SNY, PB, MAE, RMP, A-MG, CB), the School of Dietetics and Human Nutrition (SNY), and the Departments of Biology and Human Genetics (RMP), McGill University, Montreal, Canada.

Address correspondence to: C. Benkelfat, M.D., Department of Psychiatry, McGill University, 1033 Pine Avenue West, Montreal (Quebec), Canada H3A 1A1. E-mail: MDBT@MusicA.McGill.CA

Received February 5, 1996; accepted October 28, 1996. tive disorder (Benkelfat et al. 1994), but not in healthy men with no family history of major affective disorder. Taken together, these studies indicate that a clinically significant lowering of mood after ATD may be a phenotypic trait marker for depression rather than a reversal of antidepressant efficacy. The present study was designed to help distinguish between these two possible interpretations by looking at the response to ATD of remitted, medication-free patients with major affective disorder.

\section{SUBJECTS AND PROCEDURES}

\section{Subjects}

Subjects were recruited from the Royal Victoria Hospital's Mood Disorders Clinic and through local newspaper advertisements. All patients previously met DSM-III-R criteria for an episode of major depression as determined during interviews with the Structured Clinical Interview for DSM-III-R (Spitzer 1987) by a research psychologist (M.L.) in consultation with the project psychiatrist (C.B.). Twelve of fourteen subjects were interviewed with the Family Interview for Genetic Studies 
(FIGS; Nurnberger et al. 1994) with respect to diagnoses of bipolar illness or recurrent major depression in firstor second-degree relatives. The other two subjects were unwilling or unable to give sufficient information.

None of the patients were taking psychotropic medication, and all were in remission (17-item Hamilton Depression scale, HAM-D < 5, Hamilton 1960; Beigel Murphy Manic Scale, BMMS < 20, Beigel et al. 1971) for a minimum of 8 weeks before testing. Exclusion criteria included an Axis I diagnosis other than affective disorder, a family history of schizophrenia, and, for ethical reasons, being at high risk for self-injury, [i.e., those who ever attempted suicide (injured self with intent of dying) or reported having seriously considered it within the past 5 years (persistent ideation with a specific plan)]. All females ( $n=9$ ) were tested during the follicular phase of their menstrual cycle. No subjects had serous organic disorders, as determined by a physical exam and appropriate laboratory tests.

\section{Procedure}

Subjects were tested on 2 days, at least 1 week apart, in a double-blind randomized procedure identical to that described previously (Benkelfat et al. 1994). On the day before each test, all subjects ate a low-protein diet. The following morning, they consumed either a tryptophanfree amino acid drink or a similar drink containing L-tryptophan. Immediately before and 5 hours after the consumption of the drink, behavioral measurements and venous blood samples were taken. Behavioral measurements were made with the HAM-D, the BMMS, the Bipolar Profile of Mood States (POMS; McNair et al. 1988), and a Visual Analogue Mood Scale (VAMS; Bond and Lader 1974) with two dimensions, Mood and Clarity of thinking. At the end of each test day, before returning home, all subjects ate a high-protein snack and ingested a 1-g L-tryptophan tablet.

Total and free (nonalbumin-bound) plasma tryptophan concentrations were measured as described previously (Benkelfat et al. 1994). The study was approved by the Research Ethics Board of the Department of Psychiatry, McGill University, and all patients gave informed consent.

\section{RESULTS}

ATD significantly decreased plasma concentrations of free and total tryptophan ( \pm SD) by $88.1 \% \pm 5.5 \%$ and $88.3 \% \pm 5.6 \%$, respectively, whereas the balanced amino acid drink significantly increased tryptophan concentrations by $55.1 \% \pm 74.0 \%$ and $42.7 \% \pm 54.1 \%$, respectively. These changes were similar to those previously reported in healthy control subjects (Benkelfat et al.
1994; Ellenbogen et al. 1996). However, the former patients had no significant lowering of mood in response to ATD, as measured by the HAM-D, POMS (Table 1), or VAMS (data not shown). This was true irrespective of age, gender, number of episodes, time since last episode, history of mania or hypomania, family history of major affective disorder, or previous pharmacological treatment.

\section{DISCUSSION}

In this study, ATD had no effect on mood. This lack of effect is consistent with the idea that ATD causes relapse in patients newly remitted from an episode of major depression because a functional serotonergic system is essential for maintaining the effect of many antidepressant drugs. Support for this idea comes from the observation that ATD reverses the therapeutic actions of monoamine oxidase inhibitors and the 5-HT reuptake inhibitor fluoxetine, but not the antidepressant effect of the noradrenaline reuptake inhibitor desipramine (Delgado et al. 1990, 1991). Other explanations are nevertheless possible, and ATD may cause mood lowering in subgroups of medication-free patients whose characteristics have not yet been identified. For example, in our sample, age of onset was approximately 10 years younger than that seen in most studies of major affective disorder. Moreover, a preliminary report by Moreno et al. (1995) suggests that some stable euthymic patients off antidepressants do undergo temporary clinical relapse after ATD, supporting the idea that this response is not related solely to the reversal of antidepressant action. In comparison, a preliminary report from Miller et al. (1996) describes a failure to elicit clinical relapse in remitted, medication-free patients.

In conclusion, our results suggest that a personal history of major depression is not necessarily associated with clinical relapse in response to ATD, particularly in those who experienced an episode of depression of mild to moderate intensity followed by long period of remission. Thus, although low 5-HT neurotransmission is thought to play a role in major depression, in itself it does not appear to be sufficient to cause depressive symptoms, even in those with an expressed vulnerability for (past history of) major depression.

\section{ACKNOWLEDGMENT}

Preliminary data were presented at the American College of Neuropsychopharmacology meeting, San Juan, Puerto Rico, December 11-15, 1995. This work was supported by grants from the Medical Research Council of Canada to C.B., R.M.P., and S.N.Y. (MT-12502), to S.N.Y. (MT-7811), and to P.B. (MRC Scientist Award). 


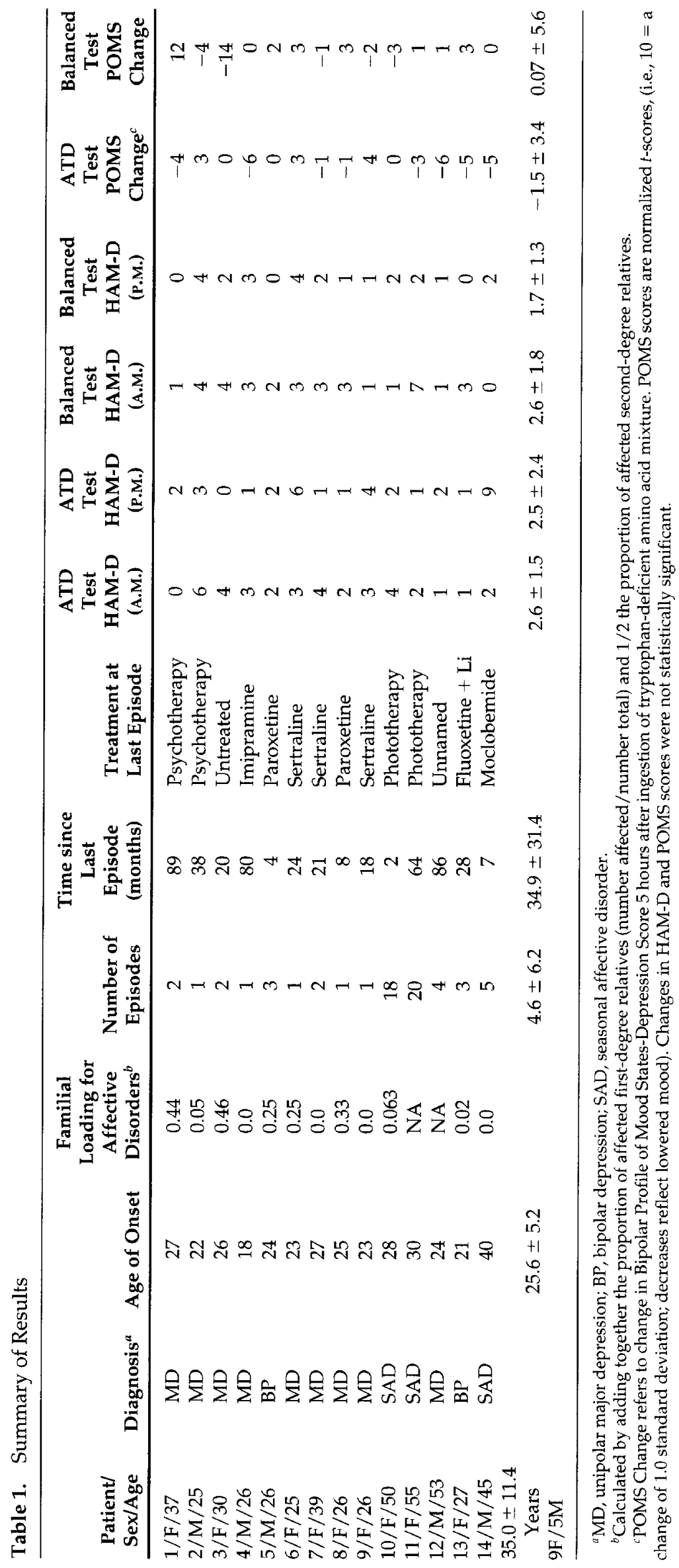




\section{REFERENCES}

Beigel A, Murphy DL, Bunney WE (1971): The Manic-State Rating Scale: Scale construction, reliability, and validity. Arch Gen Psychiatr 25:256-262

Benkelfat C, Ellenbogen MA, Dean P, Palmour RM, Young SN (1994): Mood-lowering effect of tryptophan depletion: Enhanced susceptibility in young men at genetic risk for major affective disorders. Arch Gen Psychiatr 51:687-697

Bond A, Lader M (1974): The use of analogue scales in rating subjective feelings. Br J Med Psychol 47:211-218

Delgado PL, Charney DS, Price LH, Aghajanian GK, Landis H, Heninger GR (1990): Serotonin function and the mechanism of antidepressant action: Reversal of antidepressant-induced remission by rapid depletion of plasma tryptophan. Arch Gen Psychiatr 47:411-418

Delgado PL, Miller HL, Salomon RS, Licinio J, Price LH, Heninger GR, Krystal JH, Charney DS (1991): Serotonin function and the mechanism of antidepressant action. Soc Neurosci Abstr 569.9

Ellenbogen MA, Young SN, Dean P, Palmour RM, Benkelfat $C$ (1996): Mood responses to acute tryptophan depletion in healthy volunteers: Sex differences and temporal stability. Neuropsychopharmacology 15:465-474
Hamilton M (1960): Rating depressive patients. J Clin Psychiatr 41:21-24

McNair DM, Lorr M, Droppleman LF (1988): Manual for the Profile of Mood States. San Diego, CA, Educational and Industrial Testing Service

Miller HL, Damell A, Cappiello A, Benman R, Anand A, Charney DS (1996): Serotonin function and vulnerability to depression. Biol Psychiatr 39:528

Moreno F, Gelenberg AJ, Potter R, Delgado PL (1995): Tryptophan depletion and vulnerability to depression. Am Coll Neurosychopharmacol Abstr 34:121

Nishizawa S, Benkelfat C, Young SN, Leyton M, Mzengeza $S$, de Montigny $C$, Blier P, Diksic $M$ (submitted): Differences between males and females in rates of serotonin synthesis in human brain

Nurnberger JI, Blehar MC, Kaufman CA, York-Cooler C, Simpson SG, Harkavy-Friedman J, Severe JB, Malaspina D, Reich T (1994): Diagnostic interview for genetic studies: Rationale, unique features, and training. Arch Gen Psychiatr 51:849-859

Spitzer RL (1987): Structured Clinical Interview for DSMIIIR. New York, Biometrics Research Department, New York State Psychiatric Institute 